\title{
Persistência da reality TV
}

//I/I/I/I/I/II Arlindo Machado

USP/PUCSP

\section{Marta Lucía Vélez}

Universidad de Caldas, Manizales, Colombia 


\section{Resumo}

The Up Series é a mais longa série de reality TV ainda em processo, tendo começado em 1964 e sem prazo para terminar. Ela trata do processo de crescimento de um grupo de meninos britânicos de sete anos de idade. A cada sete anos, o diretor Michael Apted retorna a esses "meninos" para saber o que aconteceu com eles durante os sete anos anteriores. O programa ainda segue sendo produzido, mas os "meninos" têm agora 52 anos. Baseado nesse programa, o artigo discute questões relacionadas com a vigilância, o voyeurismo, a invasão de privacidade, a auto-exibição pública e também a evolução técnica, política, econômica e semiótica da televisão nos últimos 50 anos. Em outras palavras, The Up Series é visto aqui como uma síntese da história da televisão e do espaço público.

\section{Palavras-chave}

The Up Series, reality TV, televisão pública, televisão privada, história da televisão.

\section{Abstract}

The Up Series is the longest-running reality TV series on television, having started out in 1964, with no time to finish. It's about the growing up of a group of British seven-year-old children. Every seven years, the director Michael Apted returns to these "children" to know what happened to them during the previous seven years. The program is still being made, but the "children" are now 52 years old. Based on this program, the article discusses questions related to surveillance, voyeurism, privacy invasion, public auto-exhibition, and also the technical, political, economic and semiotic evolution of television in the last 50 years. In other words, The Up Series is seen here as a synthesis of the history of both television and public space.

\section{Key-words}

The Up Series, reality TV, public television, private television, history of television 
O impressionante sucesso do programa holandês Big Brother (1999), que já conta com cerca de 200 edições em todo o mundo (até a época de redação deste artigo), sem contar os plágios apócrifos (com outros nomes), lançou uma luz nova sobre um formato de televisão tão antigo quanto o próprio meio, mas que até então não tinha merecido a devida atenção. Embora John de Mol, o idealizador do Big Brother original, tenha cunhado o termo reality show para designar essa forma de fazer televisão, os holandeses Meijer e Reesink (2000), organizadores do mais sério estudo sobre esse fenômeno de mídia, preferem usar a expressão reality soap, levando em consideração o coeficiente de ficção que há em quase todas as edições do programa. De nossa parte, preferimos adotar a expressão reality TV para designar não apenas os programas que seguem o formato Big Brother, mas também outros que seguem a mesma direção, embora com propósitos e conceitos diferentes.

A idéia de submeter um grupo de pessoas a uma permanente vigilância através das câmeras de televisão vem de longa data. Já na aurora da televisão, nos anos 1940, Allen Funt fez furor com seu programa Candid Camera, em que câmeras escondidas na paisagem flagravam situações cômicas ou vexatórias, sem que os seus protagonistas soubessem que estavam sendo filmados. Em geral, a produção fazia desencadear acontecimentos, para observar a reação dos protagonistas involuntários. Colocado em situação de voyeurismo explícito, o público americano se divertiu durante várias décadas com o vexame alheio e essa idéia rendeu (e ainda rende) versões as mais 
diferenciadas em todas as partes do mundo. Mas, na verdade, esse "gênero" televisual, se é que o podemos chamar assim, nasceu já na era do rádio, a partir do programa radiofônico Candid Microphone, do mesmo Allen Funt (Stark, 1997: 269). Nada de muito novo, portanto. Tudo já existia antes mesmo que George Orwell concebesse o onividente e onipresente Big Brother, em seu romance 1984.

Possivelmente, a primeira experiência explícita de vigilância auto-consentida foi o programa An American Family, exibido na televisão norte-americana em 1972, dando nascimento àquilo que Jean Baudrillard (1981: 50), por sua vez, chamou de télévision-vérité: a vida cotidiana de uma típica família americana (uma família de verdade; nada de atores, nem de ficção) observada minuciosamente em sua privacidade, por inúmeras câmeras de televisão, durante sete meses seguidos. O polêmico “seriado” produzido pela rede pública PBS mostrou não exatamente o que é, de um ponto de vista documental, uma típica família americana, mas sim o que acontece quando um grupo de pessoas é submetido sistematicamente, ininterruptamente, até mesmo na sua intimidade mais secreta, ao olhar voyeurista das câmeras que o colocam em conexão com vinte milhões de peeping toms (voyeurs, em inglês) espalhados por todo um país. De fato, a família Loud, de Santa Bárbara (Califórnia), foi destroçada pelas câmeras de televisão. O casal Bill e Pat Loud se divorciou durante as filmagens. O personagem mais sacrificado foi o filho Lance Loud, flagrado pelas câmeras numa relação homossexual e transformado em alvo de chacotas em todo o país.

Hoje os programas de vigilância auto-consentida não são tão destrutivos como An American Family porque, na verdade, são ficções disfarçadas, interpretadas por atores profissionais ou amadores, depois de meses de ensaios e leituras dos scripts. Terminam sempre com um happy end, como em qualquer telenovela. São apenas simulacros de An American Family. Mas há um outro "gênero" televisual, aparentemente inocente e inofensivo, que retoma, num sentido completamente diferente, a idéia da auto-vigilância e do voyeurismo. No Brasil ele costuma ser chamado de vídeo-cassetadas (nome popularizado no Programa do Faustão), mas a sua matriz é o America's Funniest Home Videos, série produzida pela ABC norteamericana, iniciada em 1990 e que segue sendo exibida até hoje. A idéia desse programa é simples: hoje as câmeras de vídeo estão em todos os lugares e, portanto, qualquer coisa que aconteça, da mais banal à mais insólita, está provavelmente sendo registrada, seja por 
um profissional, seja mais provavelmente por um amador. Em outras palavras, tudo o que acontece está potencialmente apto a aparecer numa tela de televisão. No limite, todos nós hoje fazemos parte desse Big Brother permanente e universal e a nossa vida privada pode, a qualquer momento, estar sendo revelada em público, através da televisão, sobretudo se contiver algum componente particularmente favorável a uma exploração espetacular.

Nossa sociedade, como já observou Michel Foucault (1988: 190), é menos a dos espetáculos do que a da vigilância. Mas a sua esperteza está em transformar a própria vigilância em espetáculo. A maioria das operadoras de cabo oferece hoje um serviço extra aos edifícios que subscrevem os seus serviços: essas operadoras destinam um ou mais canais de televisão para a visualização das câmeras de vigilância do próprio prédio. Assim, simultaneamente com o Big Brother, o espectador pode espiar também - e na mesma televisão - os seus filhos brincando no parquinho, as pessoas que entram e saem do prédio, os vizinhos tomando banho na piscina ou o que acontece na garagem, ao vivo e vinte e quatro horas por dia. A audiência desses canais nunca foi aferida pelos institutos de pesquisa, mas tudo indica que ela não deve ser muito pequena. Afinal, a televisão conseguiu fazer da vigilância uma forma de atração e de prazer escópico, de modo a generalizar a idéia de Jeremy Bentham (1829) a respeito de uma sociedade auto-vigiada: o Panóptico.

\section{Um episódio a cada sete anos}

Este artigo objetiva examinar uma série da televisão britânica conhecida como The Up Series, possivelmente a mais radical experiência de reality $T V$ já realizada e que segue ativa até hoje. Embora anterior a An American Family (a série começa em 1964, portanto oito anos antes), ela não foi concebida originalmente como uma série de reality TV, mas apenas como um ou dois documentários. Tim Hewat, um jornalista australiano que dirigia em Londres o programa World in Action, produzido pela Granada Television, teve a idéia de realizar um documentário sobre as crianças britânicas, para fazer parte de uma das edições de seu famoso programa semanal. Ele mal podia imaginar no que iria se transformar o seu documentário sobre crianças.

Nos anos 1960, a Grã-Bretanha era o centro da cultura pop. Os movimentos estudantis, as manifestações de rua contra o racismo, as 
correntes feministas, o movimento hippie e, sobretudo, a música pop ditavam as atitudes culturais e o comportamento social da juventude de todo o mundo. Nesse contexto, Tim Hewat considerou a possibilidade de realizar um documentário de prognóstico do futuro, tentando imaginar se essa revolução que estava em marcha teria algum impacto na sociedade britânica do futuro. O objetivo era indagar se a convulsão social e cultural vivida nos anos 1960 poderia mudar o rígido sistema de divisão de classes que dominou a Grã-Bretanha por cerca de 800 anos. A idéia era tomar um grupo de meninos em idade de alfabetização (sete anos) e de classes sociais diferentes e indagar qual seria o destino de cada um de seus membros na virada do século XX para o XXI, ou seja, quase quarenta anos depois. "Give me the child until he is seven and I will give you the man" (Dê-me um menino de sete anos e eu lhe devolverei um homem): foi com essa premissa (na verdade, uma corruptela de uma frase do jesuíta São Francisco Xavier) que começa uma das séries de maior duração na história da televisão mundial. Hewat queria, nesse primeiro momento, se perguntar sobre o destino dos garotos britânicos dos anos 1960: se eles teriam oportunidades idênticas, se teriam chances de vencer suas limitações de classe, sexo e cor, se seriam vencedores ou perdedores no ano 2000. "The shop steward and the executive of 2000 are now seven years old" (o líder sindical e o executivo do ano 2000 têm hoje sete anos): assim começa o primeiro episódio de The Up Series, denominado justamente Seven Up. Catorze meninos nascidos entre 1956 e 1957 são reunidos num zoológico de Londres e assim se inicia uma saga de desenvolvimentos imprevisíveis, enquanto o narrador impessoal explica: "We brought these children together, because we wanted a glimpse of England in the year 2000" (Juntamos estes meninos porque queríamos visualizar a Inglaterra do ano 2000). Essas três frases se repetiriam depois em todos os demais episódios da série.

Seven Up, levado ao ar em 1964, foi dirigido pelo canadense Paul Almond, com assistência do inglês Michael Apted. Esse primeiro episódio foi concebido como um documentário especial para a Granada Television e não como um episódio da série televisiva que se conhece hoje. Foi Denis Foreman, diretor de programação da Granada, quem convenceu Apted (Almond desistiu do projeto), cinco anos depois da emissão do primeiro episódio, a tentar descobrir o que aconteceu com esses meninos (Bruzzi, 2007: 11). Como resultado, sete anos depois (em 1970, considerando que as imagens de Seven Up foram tomadas em 1963), surge 7 Plus Seven, a conti- 
nuação do documentário anterior, com os meninos agora já adolescentes de 14 anos. O novo episódio foi dirigido por Apted, que assumiria definitivamente a condução da série. Mas até 7 Plus Seven não havia ainda a idéia de uma série. Foi depois de $21 U p$, colocado no ar em 1977, que a Granada tomou a decisão de conceber o produto como uma estrutura seriada, com um episódio novo a cada sete anos, focalizando a evolução da vida de cada um dos meninos do primeiro episódio. Essa decisão produziu mudanças radicais tanto no conteúdo, como no estilo de edição e até mesmo na maneira de (re)ler os dois documentários iniciais. Depois de 21 Up, surgiram 28 Up (1985), 35 Up (1991), 42 Up (1998) e 49 Up (2005), com promessas de continuação. O próximo episódio - 56 Up - está sendo esperado para 2011 ou começo de 2012. Com a decisão de transformar os dois primeiros documentários em episódios de uma série de reality TV (embora esse nome ainda não existisse), a vida pessoal, econômica, profissional e afetiva desses catorze meninos passou a ser monitorada ininterruptamente. Talvez os seus destinos tivessem sido completamente diferentes se a câmera indiscreta de Apted não os perseguisse periodicamente, colocando-os diante do julgamento público, como se a cada sete anos eles tivessem de revelar a toda Grã-Bretanha se triunfaram ou fracassaram.

A seleção dos meninos do primeiro episódio foi feita de forma mais ou menos cuidadosa (embora Apted se criticaria depois por ter cometido alguns erros, como veremos à frente), procurando deixar representadas todas as classes sociais majoritárias da Grã-Bretanha. Foram escolhidos quatro meninos da classe rica, sendo três de uma escola exclusiva para o sexo masculino (John Brisby, Andrew Brackfield e Charles Furneaux) e uma menina também de família próspera, Suzy Dewey. Outros dois meninos, Paul Kligerman e Simon Basterfield (este último negro), vieram de um albergue para meninos pobres ou abandonados. Quatro das crianças eram provenientes da classe trabalhadora pobre do East End, na periferia de Londres. Eram eles Tony Walker e as três inseparáveis amiguinhas: Jackie Bassett, Lynn Johnson e Sue Sullivan. Foram selecionados ainda dois garotos da classe média dos subúrbios de Liverpool: Neil Hughes e Peter Davies. Finalmente, havia mais dois meninos da classe média prestadora de serviços: Bruce Balden, que foi abandonado por seu pai, e Nick Hitchon, filho de um pequeno criador de gado.

Com o tempo, Apted (1998: 14-15) se deu conta de que a série examinava mais os pontos extremos da hierarquia social do que os seto- 
res intermediários, sobretudo a classe média, que sofreria mudanças profundas nos últimos 30 anos. Muitos setores da classe média britânica puderam conseguir títulos universitários a partir dos anos 1950, mas não havia trabalho para todos e o desemprego se tornou um problema sério nos setores especializados. Esse problema acabou não se refletindo na série. Apted também se arrepende de ter selecionado apenas quatro mulheres, pois durante o período de duração da série a inserção das mulheres na vida política e profissional foi muito intensa. De fato, em 1964 era impossível prever que uma mulher como Margaret Thatcher chegaria a primeiro ministro. Além disso, a mudança de papel da mulher ao ingressar no mercado de trabalho gerou muitos conflitos tanto na vida familiar como no próprio trabalho. As quatro mulheres que Apted selecionou não refletiram todas essas transformações: casaram-se muito jovens, tiveram filhos quase imediatamente e se dedicaram exclusivamente ao trabalho doméstico. Apenas Lynn seguiu uma carreira profissional e teve de manejar a dura conciliação da família com o trabalho.

Como se trata de um exame periódico, a cada sete anos Apted visita todos os seus protagonistas para interrogá-los sobre suas expectativas profissionais, acadêmicas e afetivas, sobre o manejo das riquezas ou da falta delas, o lugar de cada um na hierarquia social, a relação com o amor, com os filhos, os amigos etc. Ao mesmo tempo, indaga-os sobre os propósitos manifestados nos episódios anteriores e os questiona sobre se conseguiram cumprir ou não as metas projetadas. Dessa maneira, a série retorna sempre ao passado, refresca a memória de espectadores e protagonistas sobre as promessas feitas anteriormente, compara-as com a situação presente e cria expectativas para o futuro. A cada novo episódio, Apted faz um resumo do processo anterior de cada um (necessário para uma série que só acontece a cada sete anos) e avalia a sua evolução ou involução. A necessidade de ter sempre progressos para mostrar a cada sete anos exerce uma pressão às vezes insuportável na vida dessas pessoas. Elas se sentem de alguma maneira comprometidas a mostrar ao público britânico os resultados obtidos a partir dos propósitos anunciados nos episódios anteriores. É como se fosse possível assumir o controle da própria vida, para que ela possa ser exposta e examinada publicamente. Alguns protagonistas se sentem bem participando da série, sobretudo porque se tornaram figuras públicas e famosas. Outros participam sem muito entusiasmo e alguns acabam por não suportála mais e a abandonam em algum momento. Em 1963, nenhum 
daqueles meninos poderia ter consciência do que poderia significar a sua participação no programa. O que começou como um jogo divertido se converteu, para alguns, em um estímulo para avançar, mas, para outros, num fardo pesado demais para carregar. Para Apted, por sua vez, a tarefa mais difícil é encontrá-los (alguns desaparecem) e conseguir persuadi-los a colaborar a cada sete anos.

Charles Furneaux abandonou a série depois de 21 up. Foi o primeiro a fazê-lo. A partir de então é apresentado apenas através de voz over, com fotos fixas e as imagens dos três primeiros episódios. Furneaux ameaçou processar a Granada por invasão de privacidade e pediu que não exibissem mais as suas intervenções nos episódios precedentes, mas a produtora não pôde aceitar porque ele sempre aparecia nesses programas com Andrew e John. Por sua vez, a aparição de John Brisby tem sido esporádica. Ele não aceitou participar em 21 Up e 42 Up. A partir de 35 Up, as entrevistas com John passam a ser feitas por Claire Lewis, pesquisadora e produtora da série, e não mais por Apted, talvez porque as relações entre os dois se deterioraram. Mas ele regressaria à serie novamente em $49 \mathrm{Up}$, porque foi alçado ao posto de conselheiro da rainha e o prestígio público poderia lhe render dividendos políticos. Simon Basterfield não participou de $35 U p$ porque estava se divorciando e achou que esse tema lhe seria desfavorável, mas retornou em 42 Up e 49 Up. Peter Davies desistiu depois de $28 \mathrm{Up}$. À diferença dos outros, sua ausência nunca foi explicada no programa ou fora dele. Depois de $49 \mathrm{Up}$, Susy declarou não participar mais da série por não gostar da maneira como estava sendo retratada, como uma menina rica e refinada, com idéias um tanto racistas (dados extraídos de Bruzzi, 2007: 6-20).

Contrariamente a esses protagonistas, Tony Walker mostrou-se o maior entusiasta da série, pois ela influenciou positivamente sua evolução profissional e afetiva. Ele praticamente assumiu o seu papel na série como um projeto de vida. A cada novo episódio, ele conta com orgulho como cumpriu e superou todas as expectativas anunciadas anteriormente. Vive em função disso e pode-se mesmo dizer que se assumiu como personagem de um programa de TV, como o Truman Burbank (Jim Carrey) de The Truman Show (1998). Tony nasceu num ambiente pobre, mas trabalhando como taxista e poupando muito pôde construir uma vida não necessariamente rica, mas confortável. Tudo isso lhe parece um ganho, que ele faz questão de marcar como parte de um projeto de vida bem sucedido. Aparte isso, a série lhe rendeu grande popularidade, porque é o personagem 
mais animado do programa e, exatamente por isso, Apted sempre lhe dá um destaque especial. Ao final do processo, depois de famoso na Grã-Bretanha, ele acabou sendo alçado à categoria de ator de televisão, atuando em programas e comerciais como co-adjuvante. É um dos casos raros em que a participação no reality mudou radicalmente a sua vida e o transformou em estrela involuntária do espetáculo televisivo.

Neil, por sua vez, estava completamente desaparecido depois de ${ }_{21}$ Up. Nem mesmo seus pais tinham notícias dele. Depois de três meses de investigação, a equipe de produção o encontrou no norte do País de Gales, já de partida para a Escócia, onde finalmente o filmaram para $28 \mathrm{Up}$. Ele havia se transformado num homem solitário, quase um mendigo vagando sem rumo pelo mundo. Apted se interessou muito por ele e por sua insólita história de vida, sobretudo porque ela tinha um componente melodramático de fácil assimilação pela televisão. Procurou ajudá-lo onde foi possível, tornou-se seu amigo num momento de maior dificuldade e, depois de muitos contratempos, a participação na série ajudou esse personagem a recuperar o sentido de sua vida. Neil acaba por se converter no personagem mais emocionante do programa e, no final, com a ajuda também de Bruce, outro protagonista da série, dá a volta por cima e se torna um district councillor (equivalente a um vereador no Brasil, com um pouco mais de poderes) em Eden, no distrito de Cumbria, no norte da Inglaterra (Bruzzi, 2007: 13).

Com o tempo, o próprio Apted vai deixando de ser um mero apresentador ou entrevistador e se converte em mais um personagem do programa. Embora nunca o vejamos, mas apenas ouçamos a sua voz em off, alguns protagonistas se dirigem diretamente a ele e o questionam pela constante intromissão em suas vidas e pela invasão de suas privacidades. Essa interpelação direta denuncia a sua presença na cena e o transforma num personagem freqüentemente visado e referido. A partir de certo momento, o interrogador também passa a ser interrogado, o observador é também observado, além de avaliado e discutido. Nos últimos episódios, esse questionamento passa a ser frontal. Seria o caso de se examinar também o caráter obsessivo da investigação de Apted. Apesar de se ter convertido num diretor de prestígio, com um título premiado em sua carreira - Coal Miner's Daughter (1980) - além de alguns James Bond, ele jamais desistiu do projeto um tanto neurótico de perseguir esses 14 garotos ao longo de toda sua vida. 
A conversão dos dois documentários iniciais numa das mais longas séries de reality TV da história, produziu mudanças substanciais. Em primeiro lugar, ainda que o objetivo inicial de discutir as estruturas sociais e educativas da Grã-Bretanha não tenha sido inteiramente abandonado, o programa vai aos poucos se desviando para temas mais individuais e emotivos, com a intenção de explorar o melodrama televisivo, à medida que começa a ficar claro aos produtores que o seu público estava mais interessado em histórias humanas comoventes do que em temas políticos. Em segundo lugar, as mudanças sofridas pela televisão britânica ao longo da duração da série, sobretudo com a quebra do monopólio estatal e o surgimento da concorrência das redes privadas, fizeram com que os produtores começassem a se preocupar com problemas de rating (aferição de audiência), introduzindo no modelo documental inicial algumas técnicas narrativas mais modernas, encenações típicas de programas de ficção, hibridização de gêneros, edição mais rápida, incrementos tecnológicos etc. Como resultado, a diferença entre o episódio inicial (Seven Up) e o último (49 Up) é chocante. Nem parecem pertencer à mesma série.

De qualquer forma, o aspecto mais interessante de Up Series é o fato, decorrente aliás de sua longa duração (de 1964 até hoje), do programa refletir todas as transformações econômicas, tecnológicas e estéticas sofridas pela televisão ao longo desses mais de 40 anos. A série sozinha já é uma aula de história da televisão. O que começou como um documentário de fundo antropológico, de facção mais próxima do cinema da época, foi se transformando pouco a pouco num reality show sem prazo para terminar. De certa forma, isso foi o que aconteceu com a própria televisão. Dominique Wolton (1990: 23-29) divide a história da televisão européia em três grandes épocas. De 1950 a 1970, domina o modelo dito público, que tinha como ideologia a televisão como um serviço à comunidade e como vocação a produção de programas culturais e educativos. De 1970 a 1980, começa a haver o confronto de dois modelos distintos, graças ao surgimento da televisão privada e comercial, de inspiração norte-americana, que se opõe ao antigo modelo público. O modelo privado, antes rechaçado como algo demoníaco, começa a parecer, num primeiro momento, inevitável, depois irresistível e, ao final, até mesmo desejável e fascinante. De 1980 para diante, ocorre a virada radical: os governos privatizam a televisão e o modelo comercial se impõe. Essa imposição se dá menos pelas virtudes desse novo modelo e mais 
pelas insuficiências da televisão pública, que paradoxalmente passa a imitar o modelo comercial e a concorrer com ele nos (poucos) lugares em que ainda continua a existir alguma televisão pública. Imitar e concorrer significam: obsessão pelos números de audiência, redução da diversidade da programação, diminuição da produção de documentários, incremento da dose de "espetáculo" em todos os gêneros e formatos televisivos. Vale recordar que os britânicos foram os primeiros europeus que tiveram canais privados.

A partir da década de 1980, com o frisson dos canais comerciais, era preciso ser competitivo no mercado televisivo para poder disputar as fatias do bolo publicitário e isso significava ser mais incisivo na sedução do espectador. O documentário foi o gênero que mais sofreu com as mudanças, pois ele estava muito associado ao antigo modelo público. Na França, o documentário é substituído pelo conceito de grand reportage, gênero que mantém algumas características de investigação e documentação do documentário clássico, mas lança mão também de recursos narrativos dos formatos de ficção, para dar mais dinamismo às cenas e explorar melhor os aspectos emocionais e espetaculares do assunto tratado. De certa maneira, a grand reportage alude à ficção, explora a histrionice dos personagens, escolhe aqueles que são mais fotogênicos, filma-os em situação (e não apenas dando uma entrevista), decupa as cenas em vários planos previamente planejados, com diferentes ângulos, distâncias e enquadramentos e, sobretudo, mimetiza o melodrama, dando mais relevância a cenas comoventes, dramas pessoais, personagens que choram diante das câmeras e assim por diante. Embora não se possa dizer que Up Series seja uma gran reportage, ela vai adotando, à medida que evolui em direção ao século XXI, vários desses recursos descritos. Não é por coincidência que os dois personagens mais histriônicos - Tony e Neil - sejam os que vão ganhar maior destaque na série.

A partir de $28 \mathrm{Up}$, muitas cenas são planejadas e decupadas, como num filme de ficção, provavelmente com várias repetições para depois poder escolher o melhor resultado. Em $28 \mathrm{Up}$, por exemplo, Tony está chegando em casa e seus filhos correm ao seu encontro, sem que ele sequer tenha tocado a porta. Como sabiam os filhos que o pai estava chegando? As atividades de Nick na granja familiar são perfeitas demais para terem sido tomadas em situações de naturalidade. Em 21 Up, por exemplo, há um plano que mostra Nick chegando à granja num trator. A cena começa com um traveling 
sobre a paisagem rural e termina fechando a zoom justamente no momento em que aparece o trator onde Nick vem com seu pai. Uma cena claramente decupada e possivelmente repetida várias vezes.

Da mesma forma como a série vai refletindo as mudanças que se dão nos planos da linguagem e da estética televisiva ao longo do tempo, ela reflete também a evolução tecnológica da mesma televisão. Começa com imagens cinematográficas em preto e branco, editadas com corte seco, e termina com imagens digitais coloridas, processadas em edição não-linear no computador. O fato de podermos hoje ter acesso a todos os episódios através do registro em vídeo permite fazer comparações instantâneas e verificar claramente as transformações que se deram. É como se cada episódio representasse um momento diferente da história da televisão. Analisando-os, é possível ver o momento em que surge a cor na televisão, o momento em que se começa a empregar computação gráfica, o momento em que a captação da imagem passa de fotoquímica a videográfica e de analógica a digital, e assim por diante. A seguir, vamos proceder a uma pequena análise de cada episódio para ver como a série vai se transformando ao longo de seus 40 anos e como essas mudanças estão afinadas com as transformações econômicas, tecnológicas e estéticas da própria televisão.

\section{Os episódios}

Seven Up, 1964, $16 \mathrm{~mm}$, preto e branco. Documentário clássico, à maneira do cinema, com uma visualidade que lembra um pouco o primeiro filme de François Truffaut Les quatre cents coups (Os Incompreendidos/ 1959), também sobre crianças. A montagem se dá por contraponto, ou seja, uma pergunta é feita pelo entrevistador oculto e depois cada criança a responde individualmente. A sucessão das respostas ajuda a evidenciar os contrastes resultantes das origens sociais dos meninos, em função das diferenças de vocabulário, sotaque, nível de formação e expectativas de vida. Aqui predominam as perguntas curtas, o diálogo íntimo, as ações espontâneas e sem artifícios. Um entrevistador discreto estimula sutilmente os meninos e os deixa falar sem interrompê-los, deixando espaços para a reflexão. As crianças são muito espontâneas e sinceras nas suas respostas. Não há nenhuma dramaturgia planejada anteriormente, a inocência e a liberdade dos meninos se impõem. A câmera é respeitosa e distan- 
ciada, registrando apenas as atividades e brincadeiras dos garotos. Os meninos são colocados em seus contextos sociais, nas escolas, salas de aulas, lugares de brincar, dentro de suas casas, em seus bairros e arredores. Nenhum adulto aparece: nem os pais, nem os professores. São eles mesmos, os meninos, que se apresentam e se representam, fora do mundo dos adultos. As expressões, os gestos, os comentários e até mesmo o riso dos garotos neste primeiro programa serão o alicerce para a construção dos perfis e personalidades dos protagonistas nos episódios seguintes e por isso eles sempre retornam.

7 Plus Seven, 1970, $16 \mathrm{~mm}$, colorido. Os trechos preto e brancos de Seven Up utilizados aqui são agora virados para o sépia, para equilibrá-los com as imagens coloridas. Continua o diálogo direto entre o diretor e os protagonistas, sem a intervenção de outras pessoas. Tudo se baseia em perguntas do diretor e respostas dos meninos, que agora já são adolescentes. Os contextos seguem sendo neutros, com poucas ações em salas de aula, interiores de casas ou ambientes externos. Mas já se percebe aqui a insegurança dos jovens, própria dos catorze anos. Já não respondem com a mesma espontaneidade dos sete anos. A timidez os impede de serem francos e diretos, eles medem as palavras antes de falar, evitam olhar para a câmera e manifestam seu desconforto através de gestos e olhares. Começam a aparecer os primeiros lampejos de questionamento sobre as razões que os teriam levado a ser escolhidos para expor suas vidas a uma grande audiência. As imagens de Seven Up e 7 Plus Seven serão referências constantes na articulação de todos os demais episódios, segundo Bruzzi (2007: 63) porque a Granada Television destruiu os negativos que não foram utilizados na montagem final dos dois primeiros episódios e portanto não havia outros materiais.

$21 U p, 1977,16 \mathrm{~mm}$, colorido. As histórias individuais agora estão mais desenvolvidas, mas ainda se mantêm as respostas coletivas às mesmas perguntas. Há um leve incremento de seqüências com maior número de ações, para acompanhar os protagonistas em atividades esportivas, acadêmicas ou recreativas. Agora já há planejamento das sequiências, não se deixam mais as situações a sabor do acaso. Por exemplo, o programa começa com uma reunião de todos os protagonistas em uma sala de cinema para assistir à projeção do primeiro episódio. Câmeras estrategicamente colocadas na sala de projeção registram as expressões e gestos de cada um dos presentes no momento da exibição, flagrando as emoções e constrangimentos diante de suas imagens aos sete anos. Depois da projeção, há um 
coquetel onde os protagonistas conversam entre si e também com Apted (que continua não aparecendo) e essas cenas serão utilizadas como "gancho" para introduzir imagens de cada um deles nos seus contextos atuais. Agora já começa a haver decupagem das cenas e um princípio de mise en scène que denuncia a introdução de técnicas de ficção na construção do documentário, como aquela de Nick chegando de trator, que já descrevemos acima. Foi depois deste episódio que a Granada decide transformar os documentários em uma série de televisão. Este é também o último episódio onde ainda aparecem todos os catorze protagonistas originalmente escolhidos para Seven Up.

$28 \mathrm{Up}, 1984,16 \mathrm{~mm}$, colorido. Este é o capítulo que marca a transição do formato documentário para a estrutura do seriado televisivo, o que determinará mudanças profundas na forma e conteúdo da série daqui em diante. Abandona-se em definitivo a montagem por contraponto e se adota a estrutura dos capítulos independentes, um para cada protagonista. Apenas os três jovens burgueses (John, Andrew e Charles) e as três amigas da classe média (Jackie, Lynn e Sue) aparecerão juntos, cada trio em um bloco separado. No total, são dez blocos. Note-se que até então não havia blocos. Os programas eram exibidos por inteiro, sem intervalos, como se exibem os filmes nos cinemas. A noção de bloco surge por influência das televisões privadas, que precisam interromper regularmente os programas para a entrada dos breaks comerciais. Embora o programa ainda continue sendo apresentado nas televisões públicas, a necessidade de concorrer leva os produtores a adotarem modelos das televisões comerciais. Começa também a utilização de efeitos digitais, provavelmente com a ajuda da máquina ADO (Ampex Digital Optics). As vinhetas de entrada ficam mais sofisticadas: de início aparece um mural com as fotos de todos os protagonistas e, de repente, uma das fotos se destaca e avança até o primeiro plano, ocupando todo o quadro: essa foto selecionada indica quem será o protagonista do próximo bloco. Aquela câmera imóvel, íntima, com enquadramentos fechados, que marcava os primeiros episódios, desaparece por completo. Agora se dá também preferência a ações e movimentos de câmera e não apenas a entrevistas. Os personagens são mostrados em seus contextos cotidianos, bem mais complexos do que antes: trabalho, férias, amor, vida em família etc. Pela primeira vez, pessoas afetivamente envolvidas com os protagonistas (namoradas, esposas, filhos, pais, colegas e amigos) aparecem não apenas como pano de fundo, mas também 
como protagonistas, a ponto de algumas vezes ganharem tanto destaque quanto o próprio personagem que dá nome ao bloco. A vida íntima - e não mais as condições de classe - passa a ser explorada de forma obsessiva, a ponto de gerar reações por parte dos envolvidos: alguns se expõem sem nenhuma vergonha, outros se mostram mais reservados e outros ainda se tornam herméticos.

35 Up, 1991, $16 \mathrm{~mm}$, colorido. Continua o formato de capítulos independentes, um para cada protagonista, com diferentes durações, dependendo do interesse maior ou menor do personagem enfocado. Aos trinta e cinco anos, quase todos já têm família (Neil será o único que nunca a terá), muitas vezes numerosas, vidas afetivas complicadas, separações, divórcios, novas alianças amorosas. A série, mais ainda do que antes, se mostra muito interessada nos percalços da vida íntima das pessoas e se torna cada vez mais voyeurista e indiscreta. Decupagens complexas, com decomposição de ações em maior número de planos e mise en scènes explícitas são cada vez mais numerosas. A edição se torna mais dinâmica, com múltiplos jogos de planos, cortes rápidos e ágeis. A paisagem aparece agora com mais ênfase, grava-se muito mais em exteriores.

A partir deste episódio, a série dá maior ênfase a alguns personagens do que a outros, de um lado porque são os que concordam em participar e, de outro, porque suas vidas acabam se revelando mais interessantes em termos de rendimento dramático e plástico. Tony, por exemplo, é muito ativo, corre toda a cidade de Londres com seu taxi, gosta de equitação, de futebol e de sair para se divertir com a mulher e os filhos. Neil dá o necessário contraponto a esse personagem febril. Ele, ao contrário, é um homem solitário e desamparado, que perambula como um pária por paisagens distantes e inóspitas, sempre em direção a lugar algum. O caráter marginal de Neil e as paisagens desoladas por onde ele transita dão ao diretor os elementos melodramáticos para compor uma história comovente de descida ao inferno e de recuperação no final feliz. Por sua vez, Paul vive na Austrália e gosta muito de viajar em seu automóvel com sua mulher e seus filhos. As paisagens exóticas desse país e a escapada para fora do contexto britânico dão uma impressionante riqueza visual ao programa. Mais tarde, Apted convida a família australiana de Paul a ir visitar a Inglaterra e conhecer Londres pela primeira vez. Andrew tem dinheiro, viaja a Nova York, vai esquiar nas montanhas e tem uma casa de campo: mais oportunidades para incrementar o visual do programa. Bruce, sempre com idéias missionárias, viaja 
a Bangladesh para tentar cumprir seus planos comiserados de ajudar os miseráveis do planeta e, obviamente, Apted o acompanha na viagem, em busca de imagens e histórias comoventes. Jackie, ao contrário de todos esses personagens, vive só em seu apartamento, inteiramente dedicada à tarefa cotidiana de cuidar de seus três filhos. Ela não oferece muitos recursos dramáticos para segurar uma série televisiva, o que obriga Apted a criar situações, como a visita ao parque de diversões, nitidamente produzida pela equipe de televisão.

$42 U p, 1998,16 \mathrm{~mm}$, colorido. Normalmente, a série deveria acabar aqui, se levarmos em conta a premissa que aparece em Seven Up, quando o narrador diz: "We brought these children together, because we wanted a glimpse of England in the year 200o." De fato, essa era até então a idéia de Apted e da Granada Television, tanto assim que logo depois que este episódio foi ao ar, a série inteira foi lançada em DVD como que encerrando o projeto. Mas o sucesso deste episódio (e também da venda do DVD) fez a equipe mudar de idéia e dar continuidade ao programa com o $49 \mathrm{Up}$ e o prometido $56 \mathrm{Up}$. No entanto, como originalmente $42 \mathrm{Up}$ foi pensado como um episódio de conclusão, ele tem a cara de um balanço final sobre a vida desses homens e mulheres. Apted se apóia no imenso arquivo de imagens e sons que acumulou ao longo de todo seu projeto e faz uma espécie de replay de tudo o que aconteceu, na esperança de poder tirar alguma conclusão sobre o percurso dessas pessoas. Chegado a esse ponto, 35 anos depois de ter reunido os 14 garotos num zoológico de Londres, Apted já conhecia muito bem todos os seus protagonistas, já os havia seguido e analisado por toda uma vida. Ele conhecia suas fraquezas emocionais, já sabia de antemão quais seriam suas reações, detinha todas as técnicas para conseguir comovê-los, provocá-los, produzir neles o riso, a tristeza, ou as lágrimas. Tony chora quando Apted lhe pergunta sobre seus pais, Lynn fica triste quando é consultada sobre seus problemas de saúde, Neil volta a integrar-se depois de décadas de solidão voluntária, graças à intervenção de Apted. O diretor já pode manipular os seus personagens como num teatro de marionetes. Do registro documental de 1964 a este melodrama de 1998 vai uma longa distância.

$49 U$ p, 2005, vídeo digital, colorido. Primeiro programa da série captado em vídeo digital. Apted garante que isso facilitou muito o trabalho, porque ele podia deixar os entrevistados mais à vontade para falar. Antes, era preciso interromper os trabalhos a cada dez minutos para trocar os rolos de filme. Apesar disso, o resultado é um 
pouco desolador. Todos agora têm 49 anos, seus filhos já estão grandes, alguns já são avôs. A maioria é barriguda, tem a cara cheia de rugas, varizes nas pernas, os homens estão carecas e as mulheres de cabelo branco. Já não são mais engraçados ou fotogênicos e também não têm muitas novidades para contar. Apted avalia o nível de vida alcançado por cada um, seja em função do poder aquisitivo alcançado ou da situação afetiva, mas também não sabe mais o que fazer com essa gente. Tudo tem um sabor de déjà vu.

Neste episódio, alguns protagonistas aparecem muito magoados e expressam claramente o incômodo que a participação na série lhes causou. Esse é o único lado realmente interessante deste episódio, pois ele acaba funcionando como uma metalinguagem de reflexão sobre a própria série e sobre a televisão em geral. Surpreendentemente, desta vez são as mulheres que lideram os ataques. Jackie critica Apted dizendo que o programa só se interessou pelo lado privado da vida das pessoas, como os casamentos e divórcios, desentendimento entre casais, tudo isso justamente que jamais deveria ter se tornado público. Também se recorda de que, em ${ }_{21} U p$, Apted lhe perguntou se ela havia tido relações sexuais antes de casarse (esse trecho não entrou na edição daquele episódio) e revela que ficou muito incomodada com a pergunta, chegando a pedir a interrupção da gravação. De sua parte, Susy afirma que tudo foi uma experiência muito dolorosa para ela, uma experiência de que ela não desfrutou em nenhum momento. Conclui que o seu bem mais precioso é a sua privacidade e por isso jamais gostou de ter a sua vida monitorada por milhões de pessoas. Também Lynn, referindo-se a seu marido, observa que ele nunca quis aparecer no programa e que sempre considerou a Up Series uma intromissão na vida privada do casal. Mais incisivo, John Brisby observa:

I bitterly regret my headmaster pushing me forward to do the programme. I have a little pill of poison to endure every seven years... It's like Big Brother, but with the added bonus that you see people grow old, get fat, lose their hair. Fascinating, I'm sure. But does it have any value? That's another question. (Lastimo amargamente o dia em que o diretor da escola me colocou no programa. Tenho uma pequena dose de veneno para engolir a cada sete anos... É como o Big Brother, mas com o adicional de que você vê as pessoas ficarem velhas, ficarem gordas, perderem seus cabelos. É fascinante, sem dúvida. Mas isso tem algum valor? Essa é outra questão). 


\section{Os protagonistas}

Como nos seriados de ficção, Up Series utiliza recursos para caracterizar seus personagens e para que possamos facilmente nos recordar de quem são eles. Esses recursos são mais do que necessários quando nos damos conta de que é um programa que acontece uma vez a cada sete anos e ainda mais num meio tão dispersivo e desmemoriado como a televisão. Uma das maneiras de conseguir isso é escolhendo um trecho do primeiro episódio onde a criança diz alguma frase marcante e que tenha algo a ver com a sua personalidade. Esses pequenos trechos em preto e branco vão reaparecer reiterativamente ao longo de todos os sete episódios do programa. Quem não se recorda de Neil dizendo "When I grow up, I want to be an astronaut." (Quando eu crescer, quero ser um astronauta)? Ou Nick dizendo: I don't answer questions like that. (Eu não respondo perguntas como essa), quando Apted lhe pergunta se tem namorada. Ou ainda Paul dizendo "What does university mean?" (O que quer dizer universidade?), quando Apted lhe pergunta o que ele vai querer estudar quando chegar à universidade. Além de servirem como uma referência familiar para ajudar na identificação de cada um dos personagens, essas pequenas frases vão servir também de alicerce para Apted construir um perfil coerente para os seus protagonistas. Afinal, só mesmo um menino pobre, proveniente de um orfanato, poderia não saber aos sete anos o que é uma universidade. 


\section{Bruce}
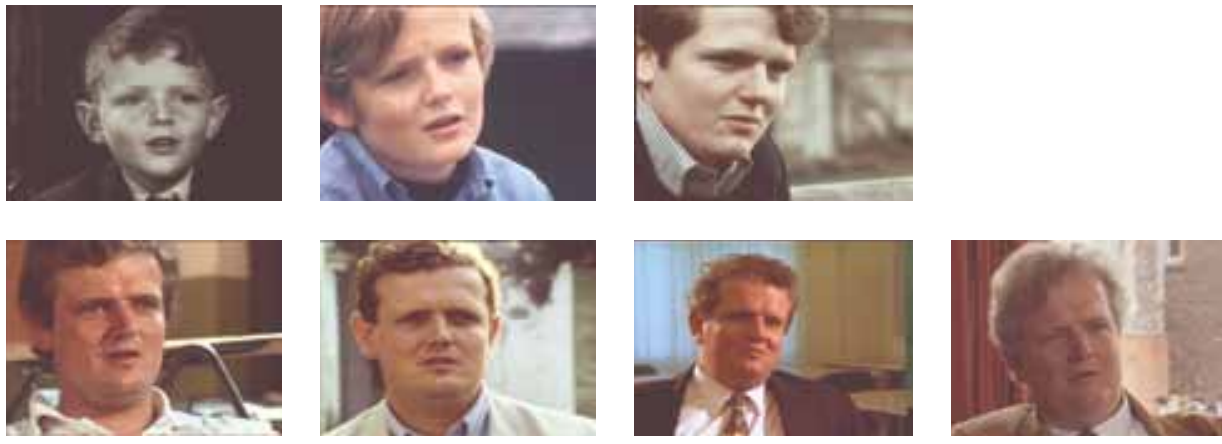

Bruce, juntamente com Nick, forma o time dos dois meninos provenientes da classe média. Logo no começo do primeiro episódio, quando Apted lhe pergunta quais eram seus planos para o futuro, Bruce responde: "Well, I'll go into Africa and try to teach people who are not civilized to be more or less good." (Bem, eu irei para a África para tentar ensinar as pessoas que não são civilizadas a serem mais ou menos boas). A reiteração dessa frase em todos os episódios vai caracterizar esse personagem como um eterno missionário e ele mesmo vai acabar assumindo esse destino, não se sabe se por vocação ou por influência da série. Acaba se dedicando à docência em escolas públicas destinadas a crianças pobres e imigrantes. Aos 21 anos, cursava o último ano de matemática em Oxford e aos 28 ensinava em escolas públicas de Londres. Aos 35, viajou para Sylhet, um vilarejo ao nordeste de Bangladesh, para ensinar em uma escola, sempre acompanhado pela câmera de Apted. Numa das cenas desse episódio, o diretor lhe pergunta se o seu sonho missionário finalmente se concretizou e Bruce responde: "Well, not exactly. I'm a teacher now in London, and I've had the opportunity to come here for a term. It just so happens the school I am in has great links with this part of the world, and I've come here to find out about the background of many of the boys that I teach back in London." (Bem, não exatamente. Atualmente sou professor em Londres e tive a oportunidade de vir aqui por um período. O que acontece é que a escola onde eu trabalho tem grandes ligações com esta parte do mundo e então eu vim para cá para entender as origens de muitos dos garotos a quem eu ensino em Londres). Casou-se um tanto tardiamente e o seu casamento foi filmado para $42 \mathrm{Up}$, tendo Neil como padrinho (situação nitidamente arranjada para a série). Em 49 Up já tinha dois filhos. 


\section{Nick}
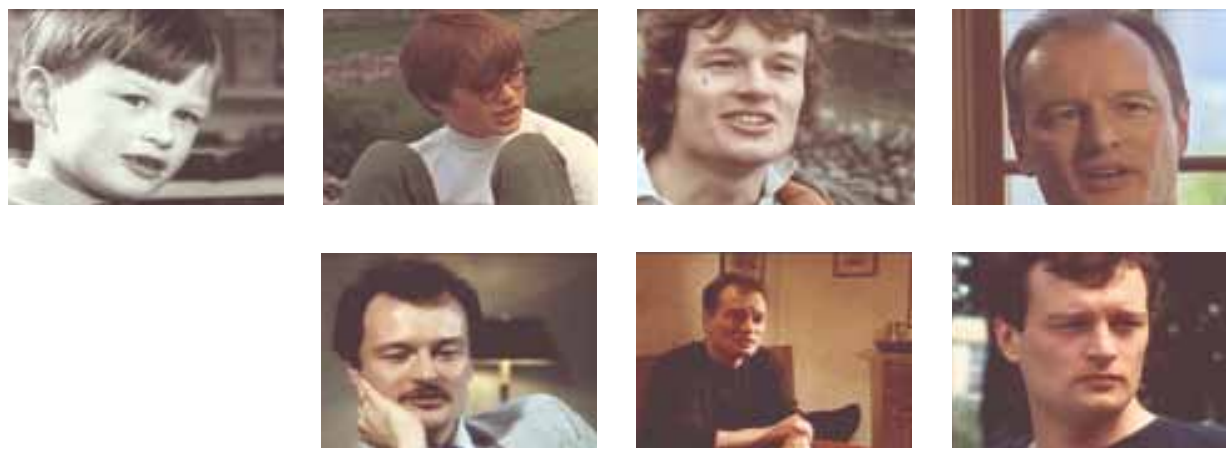

Nick nasceu e cresceu no campo, em Yorkshire Dales, no norte da Inglaterra, onde seus pais criavam vacas e ovelhas, mas ele preferiu se dedicar mais aos estudos e acabou se tornando um cientista. Seus primeiros anos de escolaridade foram cumpridos numa escola rural perto de sua casa de campo. Aos 21 anos, cursava o segundo ano de Física em Oxford. Aos 28, já era professor assistente na Universidade de Wisconsin, nos Estados Unidos, onde fazia experimentos buscando produzir energia atômica livre de radioatividade. Casou-se com Jackie, que havia conhecido em Oxford, e com ela teve um filho. Aos 35 anos, já estava separado e foi promovido a professor associado em sua mesma universidade. Nick é o personagem que mais questiona Apted durante toda a série. Em 35 Up, o diretor pergunta a cada um dos protagonistas qual havia sido o impacto causado pela sua participação na série e Nick lhe responde: "We were talking about my ambitions as scientist. My ambitions as scientist is to be more famous for doing science than for being in this film. But unfortunately, it's not going to happen" (Estávamos falando sobre minhas ambições enquanto cientista. Minha ambição enquanto cientista é tornar-me mais famoso fazendo ciência do que fazendo este filme. Mas desgraçadamente isso não está acontecendo). Aos 42 anos, a série o ajudou (financeiramente inclusive) a visitar sua antiga casa em Yorkshire Dales e ali foi feita a entrevista para o episódio $42 \mathrm{Up}$, como em Seven Up. Em uma entrevista que deu a Stella Bruzzi (2007: 59) em 2006, ele confessou: "Seven days every seven years, it's very biblical and weird... You live a completely normal existence for seven years and then they descend on you for seven days. Suddenly you're transported into this alternative universe... A really very special place." (Sete dias a cada sete anos, isso é muito bíblico - e estranho... Você vive uma 
existência completamente normal durante sete anos e então eles baixam sobre você durante sete dias. De repente, você é transportado a esse universo alternativo... Um lugar realmente muito especial).

Suzy
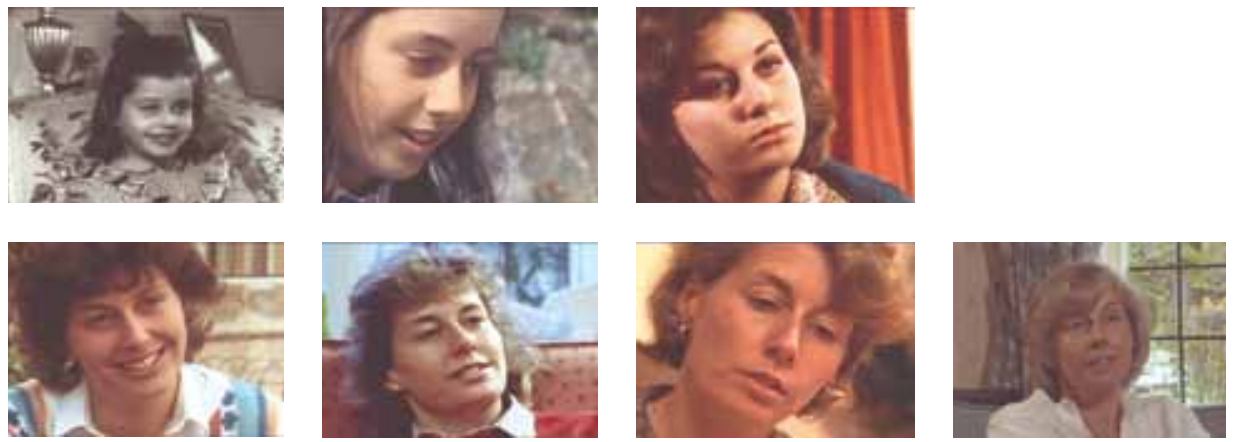

Suzy, juntamente com Andrew, John e Charles, forma o time dos meninos burgueses e bem nascidos. Ela provém de uma família particularmente privilegiada na Grã-Bretanha, mas, como costuma acontecer nessas famílias, sempre foi uma menina muito solitária e praticamente foi criada por sua babá. Muito cedo a mandaram estudar num colégio interno, o que a fez sentir-se abandonada pelos pais, pois só os podia ver nos períodos de férias. Não freqüientou universidade. Aos 22 anos, trabalhou como secretária em Londres. Aos 28, já estava casada com Rupert Dewey, um conhecido advogado de Bath, cidade costeira ao sudoeste da Inglaterra. Juntos tiveram três filhos. A partir de então, tornou-se apenas uma dona de casa, dedicada a cuidar dos filhos. Por sua vontade, jamais mandaria seus filhos a um colégio interno. Como Nick, também costuma questionar Apted e sua série. Já aos 14 anos, Apted lhe perguntou: "What do you think about making this program?" (O que você acha de estar fazendo este programa?). E Susy lhe responde: "I think it's just ridiculous. I don't think there's any point in doing it." (Eu acho simplesmente ridículo. Não vejo nenhuma razão para fazê-lo). Apted insiste: "Why not?" (Por que não?). E Susy responde: "Well, what's the point of going into people's lives and saying: Why do you do this? And why you do that? I don't see any point in it." (Bem, qual é a razão para entrar na vida das pessoas e perguntar-lhes: Por que você faz isso? E por que você faz aquilo? Não vejo nenhum sentido nisso). 
John, Andrew e Charles
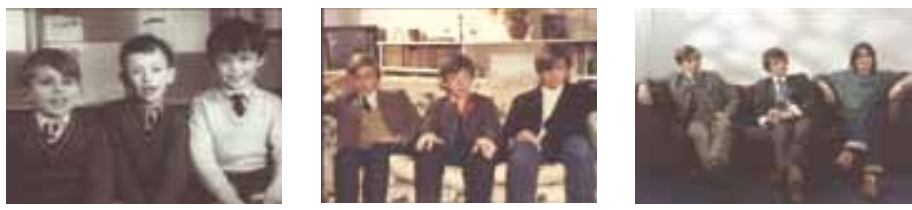

John
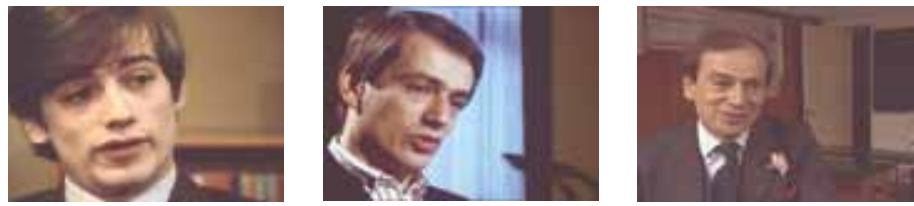

\section{Andrew}
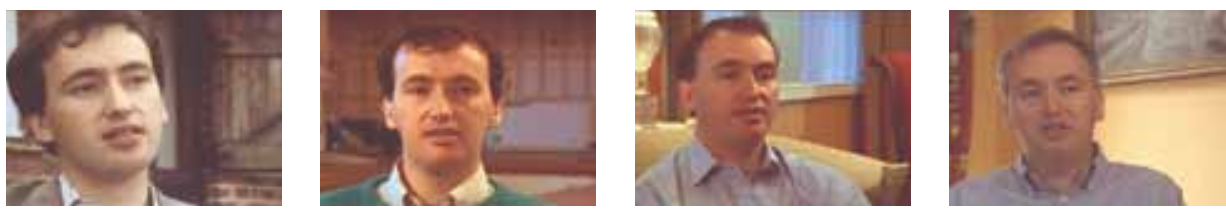

\section{Charles}
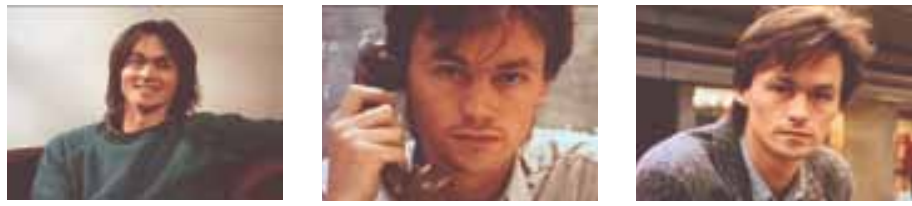

Andrew, John e Charles são os três meninos ricos selecionados em um mesmo colégio masculino em Kensington, a oeste de Londres. Nos três primeiros episódios são apresentados sempre juntos, sentados em um sofá, em geral falando de temas econômicos. Aos sete anos, o entrevistador pergunta: "Do you read newspapers?" (Você lê jornais?). Andrew responde: "I read the Financial Times." (Eu leio o Financial Times). E John: "I read the Observer and the Time." (Eu leio o Observer e o Time). Isso aos sete anos! Compare-se com Paul, que nem sabia o que era universidade... Aos 21 anos, Andrew estu- 
dava advocacia no Trinity College, em Cambridge. Aos 28, já trabalhava como advogado em uma grande empresa de Londres. Aos 35, era sócio de uma empresa de advocacia. Ele casou-se com Jane, que deixou o trabalho para dedicar-se apenas ao lar. Nos fins de semana, o casal costuma freqüentar uma casa de campo. Em $42 U p$, Apted acompanhou o casal a uma viagem a Nova York. Andrew é o único dos três burgueses que concordou em participar de todos os episódios da série, abrindo sua vida pessoal e profissional às câmeras de Up Series. John, ao contrário, participou de poucos programas e os fragmentos em que aparece são curtos e geralmente gravados fora dos lugares que ele costuma freqüentar. Graduou-se em Oxford como advogado. Aos 28 anos, começou sua carreira como juiz na corte. Aos 49, fazia parte do conselho da rainha. Casou-se com a filha de Sir Donald Logan, ex-embaixador da Grã-Bretanha na Bulgária. Charles, finalmente, e como havíamos apontado antes, só participou da série até 21 Up. Não estudou em Oxford ou Cambridge como os outros, mas na Durham University. Trabalhou inicialmente em alguns jornais de Londres, depois foi contratado como produtor na rede $\mathrm{BBC}$ de televisão e finalmente se converteu em editor de documentários de ciências para o Channel Four.

\section{Jackie, Lynn y Sue}
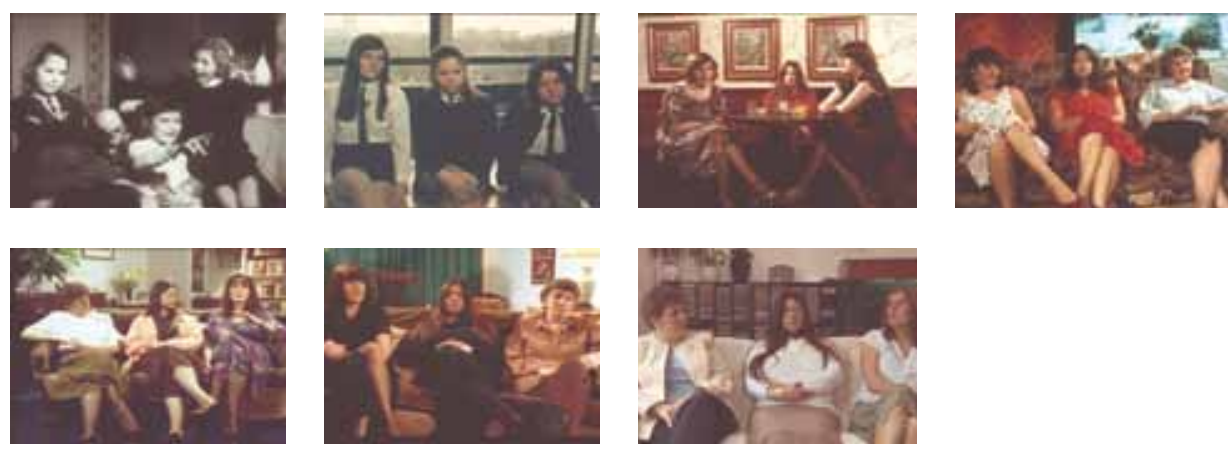

Jackie, Sue e Lynn são as três inseparáveis amigas do East End, na periferia de Londres, bairro de classe média baixa. Tal como os três burgueses, elas também são apresentadas juntas na maior parte das vezes e também sempre sentadas em um sofá, talvez por uma intenção irônica por parte de Apted de explorar o contraste. De fato, a maneira de falar, expressar-se e de vestir dos dois trios, além da 
decoração dos respectivos ambientes, criam um contraste bastante nítido entre os dois grupos sociais, ainda que a mise en scène seja a mesma. Jackie, aos 14 anos, estava estudando na St. Paul's Way Comprehensive School (escola secundária) e, aos 21, já havia se casado com Mick, que conheceu em um bar. Aos 28, trabalhava em uma companhia de seguros e vivia em Londres. Aos 35 anos já havia se divorciado de Mick e tinha um filho que não era dele. Aos 42, tinha mais dois filhos e vivia com o pai desses outros. Lynn, por sua vez, já havia finalizado o primeiro grau (grammar school) aos 14 anos. Seu pai era carvoeiro e ela se lembra de vê-lo chegar em casa sempre com a cara negra. Aos 21, já havia se casado com Russ, que conheceu na escola e depois trabalhou com ela numa livraria do East End. Aos 28 anos, tinha duas filhas: Emma e Sarah. Aos 35, estava trabalhando numa biblioteca móvel. Aos 42, havia perdido o pai carvoeiro. Sue, por fim, era filha de um marceneiro e viveu a vida toda no East End. Aos 21 anos, trabalhava em uma companhia de viagens. Aos 28, já havia se casado e tinha um filho. Aos 35, tinha se divorciado e estava com mais outro filho de um novo marido. Aos 42, vivia apenas com seus dois filhos e tinha algumas relações amorosas esporádicas. Aos 49, estava com um novo companheiro e um cachorrinho que ela apresenta no programa como sendo seu novo bebê.

\section{Tony}
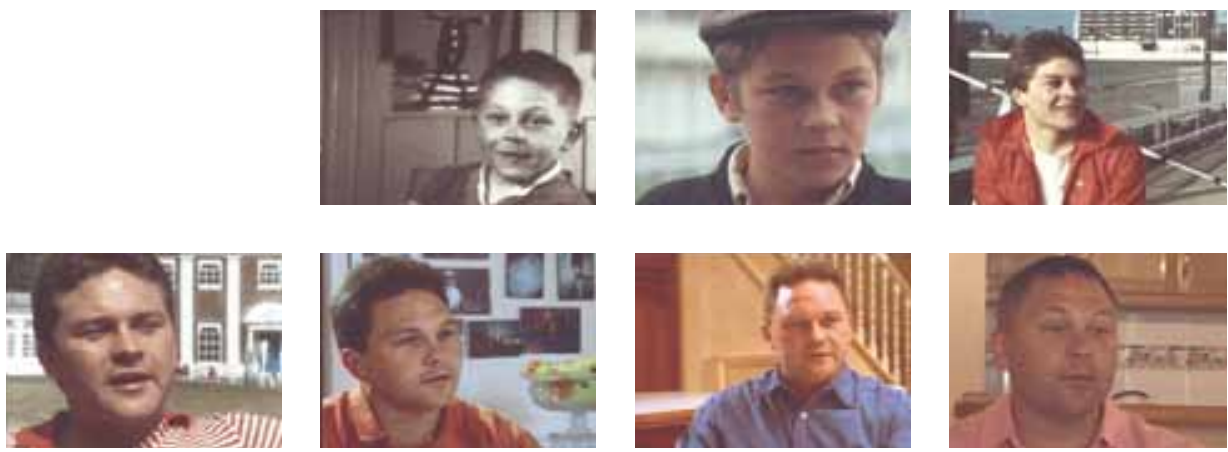

Tony foi o que mais cumpriu os prognósticos dos primeiros episódios. Aliás, seu propósito de vida era mostrar que podia cumprir o que prometia, pois ele praticamente vivia em função da série. Em Seven Up, dizia que queria ser um jockey. De fato, aos 14 anos estava treinando para ser jockey e até conseguiu participar de três corridas. 
Quando, em Seven Up, o entrevistador lhe pergunta o que ele seria se não conseguisse ser um jockey, ele respondeu que seria um motorista de taxi. E de fato foi. Aos 28 anos, tinha o seu taxi particular, mas continuava treinando para ser jockey. Aos 35, dividia o trabalho de taxista com sua esposa Debbie e já tinha três filhos. Aos 49, mostra com orgulho os resultados de seus esforços: tem uma casa de férias na Espanha, é ator de televisão e já tem dois netos. Ao final, ele, Debbie e os filhos conseguem atingir uma vida pequeno-burguesa confortável, embora um tanto óbvia. Tony faz o papel do tipo esforçado, que trabalha muito e que precisa mostrar progressos em cada novo episódio. É o personagem mais histriônico da série e expõe a sua intimidade sem nenhum pudor. Desde Seven Up, já se pode notar seu caráter extrovertido e hiperativo, principalmente quando aparece correndo, pulando muros e esmurrando um companheiro de classe. É o único que publicamente admite gostar de Up Series, porque ela deu lhe deu razões para batalhar e lograr seus êxitos econômicos. Apted se apaixonou particularmente por este personagem e, por essa razão, Tony sempre tem blocos muito mais extensos que qualquer outro.

\section{Simon}
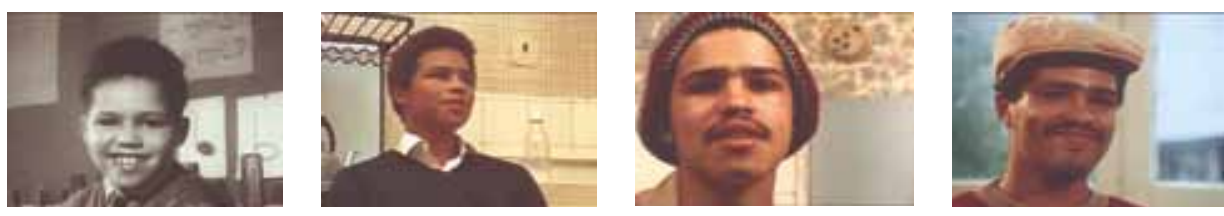

Simon, junto com Paul, faz o time dos meninos oriundos de um orfanato em Middlesex. Filho de mãe solteira, nunca conheceu o pai, de quem herdou a cor negra. Cresceu nesse albergue para meninos pobres, onde viveu muito conflitos, principalmente nas mãos de um supervisor autoritário. Ele conta que uma noite, por castigo, o supervisor o colocou para engraxar todos os sapatos da casa, ao todo cinqüenta pares. Aos 21 anos, trabalhava como operário em uma empresa de alimentos. Aos 28, vivia com sua mulher Ivonne e já tinha cinco filhos! Aos 42 e 49, aparece com uma nova mulher, com quem teve outro filho. Nessa época, trabalhava conduzindo um carro de carga em uma empresa. Faz parte do time dos fracassados da série, aqueles que, se fosse no Big Brother, seriam postos para fora do jogo logo no começo do programa.
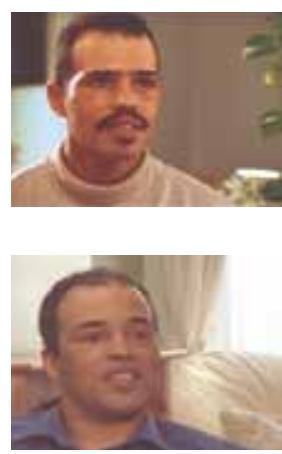


\section{Paul}
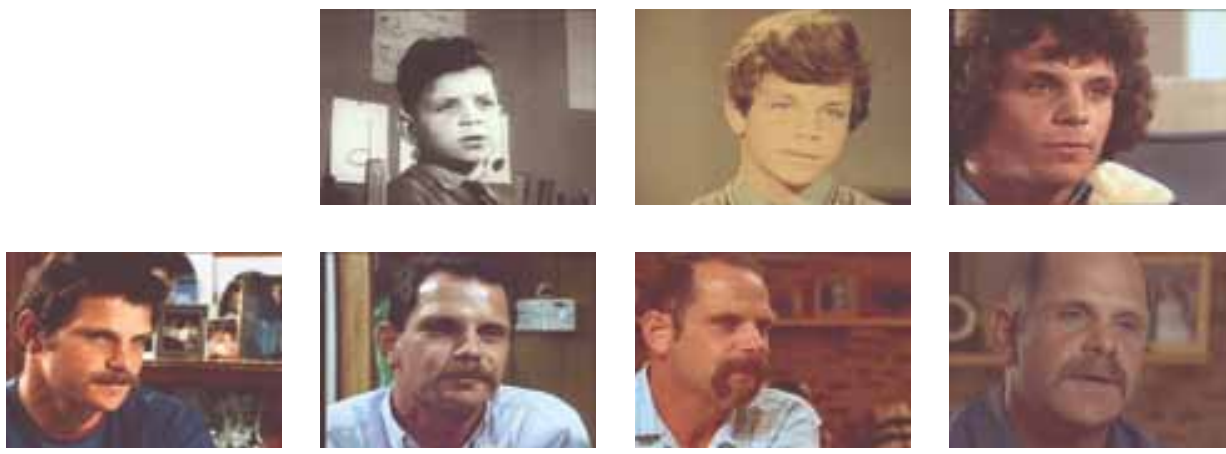

Paul viveu sua infância em Londres, com seus pais e um irmão, mas depois do divórcio de seus pais, foi enviado ao mesmo albergue onde viveu Simon, local em que também teve uma vida infeliz. Aos 14 anos, havia se mudado para Melbourne, na Austrália, onde passou a viver com seu pai, seus irmãos e sua madrasta. Deixou a escola aos 16 anos. Aos 21, trabalhava como pedreiro em construções civis. Aos 28, havia se casado com Susan e já tinha dois filhos: Katie e Robert. Aos 35, a produção da série levou toda a família para conhecer Londres. Aos 42 , dá-se conta de que sempre foi instável no trabalho e de que nunca ficou mais que três anos em um emprego, pois se desmotiva muito facilmente. Em 21 Up e 49 Up, a produção da série promove encontros entre Paul e Simon, tentando reaproximá-los. Mas depois das filmagens de 42 Up, Paul é submetido a um tratamento médico, devido à forte depressão. Enfim, como Simon, é outro fracassado.

\section{Neil}
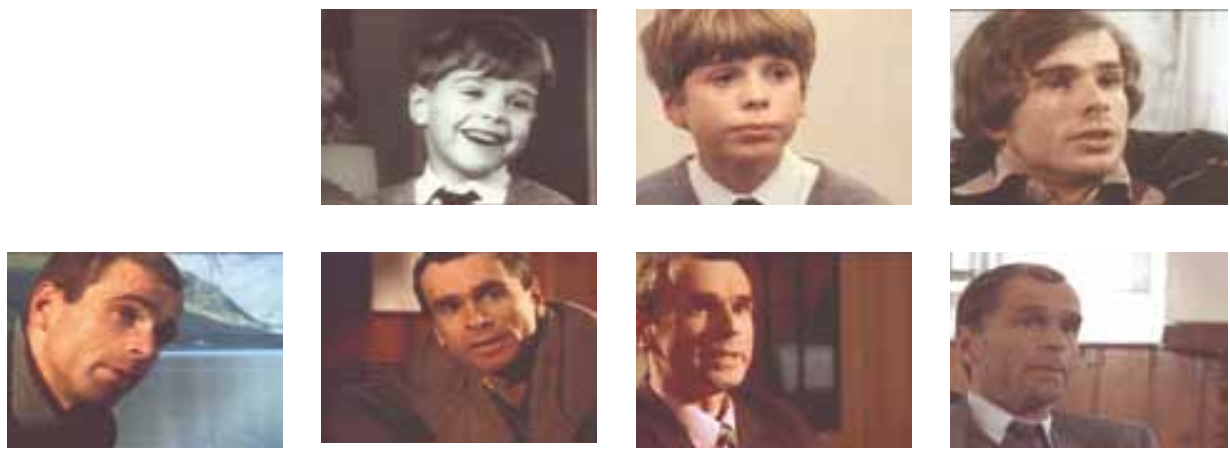
Neil compõe com Peter o time dos dois meninos de Liverpool. Ele cresceu com seus pais, ambos professores em Woolton, nos subúrbios de Liverpool. O que mais lhe agradava era viajar de trem. Aos 14 anos, estudou em um colégio em Liverpool. Aos 21, queria ir estudar em Oxford, mas não conseguiu. Alternativamente, entrou na Aberdeen University, onde ficou por pouco tempo. Durante esse tempo, vivia em albergues do Estado e tinha trabalhos ocasionais. Aos 28, era quase um indigente, depois de perambular pela GrãBretanha, sem rumo e sem residência fixa. Durante sete anos, viveu nas montanhas ao oeste da Escócia, com o dinheiro que conseguia do seguro social do Estado (espécie de salário-desemprego). Aos 35, vivia num trailer, no arquipélago de Shetland, ainda às custas do Estado. Com a ajuda de Bruce e da produção de Up Series, é levado a Londres e, a partir de lá, muda significativamente de status, terminando como district councillor em Eden, como já apontamos acima. Foi padrinho de casamento de Bruce, personagem que sempre procurou ajudá-lo. Nunca se casou ou teve namorada e sente falta da presença feminina em sua vida. Afirma-se cristão e sempre faz questão de salientar que isso o ajudou a manter-se mentalmente equilibrado, embora, nas entrevistas, tenha mencionado, algumas vezes, intenções de suicídio. A trajetória de Neil foi, sem dúvida, a mais imprevisível de todo o grupo. Aos 49 anos, inesperadamente, ele dá a volta por cima, aparece fazendo um discurso na Câmera de Representantes de Eden, apresenta-se bem vestido e ostenta um carro particular novo.

\section{Peter}
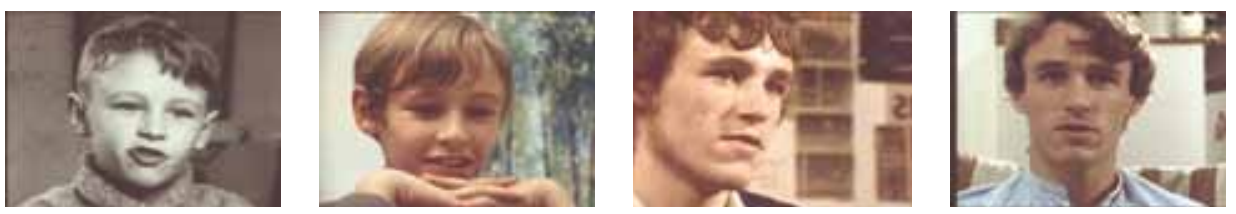

Peter também é de Liverpool, como Neil. Aos 21 anos, já estava casado. Aos 28, ganhava uma miséria como professor num colégio privado. Sem nenhuma explicação oficial, ele desaparece depois de 28 Up. A ausência de Charles Furneaux, que também abandonou a série a partir de 21 up, é sempre explicada em cada episódio, mas a ausência de Peter é simplesmente ignorada. Na Wikipedia, aparece 
uma explicação, evidentemente não documentada ou comprovada: ele cai fora da série porque criticou o governo de Margaret Thatcher em um tablóide e com isso perdeu o emprego de professor. Não se sabe se o seu desaparecimento da série foi decisão do diretor ou dele mesmo.

\section{Considerações finais}

Como aconteceu com Big Brother, Up Series também teve inúmeras outras versões em países tão diferentes como Alemanha, Rússia, África do Sul, Japão, Estados Unidos, Austrália, França, Dinamarca e Holanda, sem falar de uma nova versão britânica, que começou em 2000 com 7 Up 2000 e continuou em 2007 com 14 Up 2000, sob direção de Julian Farino. Muitas das versões não britânicas tiveram supervisão do próprio Michael Apted. O interesse pela fórmula inventada pela Granada Television demonstra a sua eficiência como espetáculo audiovisual. Vale ressaltar também que a duração de cada episódio de Up Series vai aumentando gradativamente ao longo do tempo: Seven Up tem apenas 39 minutos, enquanto os quatro últimos episódios passam dos 130 minutos cada um e são divididos em duas ou três partes para emissão em dias diferentes. Isso demonstra que o interesse pela série foi crescendo gradativamente, a ponto de sugerir aos produtores que eles poderiam tirar melhor proveito desse crescimento.

A reality TV é, de um lado, um formato genuinamente televisivo, porque se vale da característica principal desse meio que é a serialidade, ou seja, o fato dos programas serem seccionados em capítulos ou episódios, cada um deles mostrado num dia, mês ou ano diferente. A reality TV transforma a temporalidade da televisão em sua própria forma e conteúdo. No caso de Up Series, temos uma serialidade radical, porque o intervalo de tempo entre os capítulos é de sete anos (não há outro programa com uma estrutura seriada tão extrema assim), com riscos relacionados com a memória e fidelidade da audiência, desinteresse dos protagonistas em continuar e até mesmo o possível falecimento de alguns participantes, o que até agora, por sorte, não aconteceu. Mas somente essa serialidade radical poderia permitir essa coisa até então insólita que é acompanhar a vida de um grupo de pessoas por quase meio século.

Por outro lado, a reality TV inverte aquilo que sempre foi considerado o sentido original da televisão: em vez de ser um veículo que traz as notícias do mundo exterior para a intimidade da família, 
ela, ao contrário, leva a intimidade da família para o exterior e expõe publicamente o que antes era privado e secreto. É como se, na reality $\mathrm{TV}$, as casas dos participantes tivessem todas as paredes de vidro e fossem transparentes. O meio doméstico por excelência acaba por "domesticar" a esfera púbica. Hoje, essa tendência se alastra não apenas dentro da televisão, através dos reality shows, das "videocassetadas" (home videos) e dos shows de câmeras ocultas, mas também na internet, através dos blogs, fotoblogs, web câmeras e sites como You Tube e Orkut, que exibem diariamente, 24 horas por dia, a banalidade do cotidiano íntimo de cada um.

O planeta não se converteu em uma aldeia - afirma Paula Sibilia (2008: 73) - mas em uma gigantesca alcova global, com cada um de nós assistindo, pela televisão, confortavelmente instalados em nossos quartos próprios, a um show de intimidades alheias.

Resta saber o que restou dos propósitos originais de Seven Up, afirmados por Tim Hewat em 1964. A sociedade britânica mudou nesses quase cinqüenta anos? Pouca coisa, pelo que parece. A rígida divisão de classes, que era o tema inicial, parece ter permanecido intacta. Os que nascem pobres permanecem pobres, multiplicam a pobreza e não conseguem sair desse beco sem saída. O mesmo acontece com os ricos e os remediados. Tony poderia ser visto como a única exceção, mas uma exceção que não elimina a regra. Neil, apesar de uma aparente crescida no final, continuou um eterno desempregado. Parece que a revolução cultural dos anos 1960 não deixou marcas na civilização dos antigos celtas. O que houve apenas é que os Rolling Stones se tornaram velhos e chatos.

No mais, a série permite analisar aspectos importantes da evolução da televisão, sobretudo da televisão européia, deixando bastante nítido o impacto que a privatização dos serviços produziu na história recente desse meio. As metamorfoses que a série foi sofrendo ao longo de toda a sua duração não foram jamais arbitrárias, mas refletem os múltiplos aspectos da evolução da televisão como um todo, como a mudança dos modelos de gerenciamento e financiamento, o surgimento da competitividade no mercado televisivo, a imposição das pesquisas de audiência (rating) como critério para a continuidade dos programas, os avanços nos planos narrativos e tecnológicos e assim por diante. 


\section{Bibliografia de referência}

APTED, Michael 1998. 42 Up. New York: New Press.

BAUDRILLARD, Jean. 1981. Simulacres et simulation.

Paris: Galilée.

BENTHAM, Jeremy.1829. Oeuvres. Bruxelles: Louis Hauman.

BRUZZI, Stella. 2007. Seven Up. London: British Film Institute.

FOUCAULT, Michel. 1988. Vigiar e Punir. História da Violência nas Prisões. Petrópolis: Vozes.

MEIJER, Irene Costera (en) Maarten Reesink. 2000. Reality Soap. Big Brother en de Opkomst van het Multimediaconcept. Amsterdam: Uitgeverij Boom.

SIBILIA, Paula. 2008. O Show do Eu. A Intimidade como Espetáculo. Rio de Janeiro: Nova Fronteira.

STARK, Steven.1997. Glued to the Set. The 6o Television Shows and Events that Made Us Who We Are Today. New York: Free Press.

WOLTON, Dominique (1990). Éloge du grand public. Une théorie critique de la télévision. Paris: Flammarion. 